\title{
Estimating the New Keynesian Phillips Curve by Quantile Regression Method for Turkey
}

\author{
Çiğdem Boz \\ Department of Economics, Maltepe University, Maltepe, Turkey \\ Email: cigdemboz@maltepe.edu.tr
}

Received July 25, 2013; revised August 25, 2013; accepted September 4, 2013

Copyright (C) 2013 Çiğdem Boz. This is an open access article distributed under the Creative Commons Attribution License, which permits unrestricted use, distribution, and reproduction in any medium, provided the original work is properly cited.

\begin{abstract}
New Keynesian Phillips Curve based on nominal rigidities and rational expectations is a widely used structural model of inflation dynamics in the analysis of monetary policy. It postulates that current inflation is determined by expected inflation and by the real marginal costs. This study uses the Quantile Regression Method (QRM) to present the New Keynesian Phillips Curve (NKPC) estimation for Turkey instead of Generalized Method of Momentum (GMM). This method identifies differences in response of the inflation to changes in explanatory variables at various points of inflation.
\end{abstract}

Keywords: Quantile Regression; New Keynesian Phillips Curve; Turkish Economy

\section{Introduction}

The New Keynesian Phillips Curve (NKPC) which is based on nominal rigidities and rational expectations is a widely used structural model of inflation dynamics in the analysis of monetary policy. It postulates that current inflation is determined by expected inflation and by the real marginal costs as the driving variable. Despite it has a commonly accepted theoretical background, there have been controversial results regarding its empirical validity $^{1}$. In the literature, the Generalized Method of Momentum (GMM) has been extensively used to estimate NKPC in order to avoid endogeneity bias caused by expected inflation, since it is likely to produce imprecise and biased estimates ${ }^{2}$. One of the GMM assumptions specifies that the coefficients are evaluated when the level of inflation is at the mean of the distribution conditional on its explanatory variables. In this paper, we would like to contravene this assumption and examine the response of the inflation rate through different quantiles of its distribution.

\footnotetext{
${ }^{1}$ Gali and Gertler (1999) and Gali, Gertler and Lopez Solido (2001) find that the pure NKPC where inflation is a function of expected future inflation and real marginal costs, is good approximation of inflation dynamics in both the US and Europe. However, Roberts (2001) provides evidence against the NKPC with only forward looking elements using GMM, although in contrast to Fuhrer (1997) he finds there to be clear role for forward looking behavior.

${ }^{2}$ As a solution for this problem, Linde suggests FIML but this method has not been used extensively.
}

Turkish economy has experienced high inflation periods especially before the adoption of Inflation Targeting (IT) regime in 2002, later on the inflation rate gradually decreased. Although the inflation rate is relatively low and stable in comparison to the past, they range from $29.7 \%$ to $6.2 \%$ between 2002 and 2012 . This trend leads us to think over that the marginal effects of explanatory variables on the inflation rate across its distribution could be different. In order to analyze these effects at various points of the inflation rate, we estimate the hybrid version of the NKPC employing Quantile Regression (QR) that takes into account endogeneity issues. Findings from our estimations show that the marginal effects of explanatory variables on the inflation rate through its distribution are varying. When the inflation rate is low, the backward looking term is significant, notwithstanding forward looking term is insignificant. But when the inflation rate is high, the significance of forward looking term dominates the backward looking term. In addition, the significance of output gap and exchange rates increases for high inflation. It reflects that the inflation rate is relatively more driven by lagged inflation when the inflation rate is low, but on the contrary, it is relatively more driven by the policy rate and forming of economic agents' inflation expectations when the inflation rate is high.

The following section provides the overview of the literature on the NKPC. Emprical analyses and findings are described in the third section. The final section con- 
cludes the paper.

\section{Evolution of the Phillips Curve and Literature on NKPC}

The relationship between inflation and real variables is very important for understanding the effects of monetary policy. The Phillips curve, one of the most famous relationships in macroeconomics, is concerned with this issue. In 1958, A. W. Phillips's work demonstrated that lower unemployment leads to higher wages. Following the influential contribution from Samuelson and Solow, the Phillips Curve was interpreted by many orthodox Keynesians as implying a stable long-run trade-off which offered the authorities a menu of possible inflation-unemployment combinations for policy choice [1]. The idea of a stable trade-off between inflation and output was challenged independently by Milton Friedman and Edmund Phelps who both denied the existence of a permanent (long-run) trade-off between inflation and unemployment. In other words, expectations augmented PC was vertical at the natural rate of employment.

However by the late 1960s and early 1970s, both inflation and unemployment had begun to increasing, and this phenomenon named as stagflation, discredited Friedman and Phelp's view. The economists of New Classical School which is the dominant paradigm in 1970s, went further and claimed that fiscal or monetary policies could have no impact on output or employment in short-run and either long-run as a consequence of rational expectations together with instantaneous market clearing assumptions. Yet, this policy ineffectiveness proposition conflicted with the empirical evidence on the efficiacy of monetary policies on real variables.

As a reaction to this proposition, in 1990s, New Keynesian models based on prices and wages rigidities and rational expectations have been widely acknowledged. In order to explain the effects of nominal variables on real variables, New Keynesian Phillips Curve (NKPC) which is based on Taylor [2], Rotemberg [3] and Calvo [4], was suggested. According to the NKPC, current inflation is expressed as a function of expected future inflation and real marginal costs. The prior theories concerning inflation dynamics, neoclassical Phillips Curve, assume flexible prices and rational expectations in a microfounded framework. But the predictions of this model conflicted with the realities; data about the real effects of money are much stronger than what this model implies. To be able to explain the stronger nominal effects on real variables the NKPC stressed the role of staggered wage and price setting of forward looking individuals and firms by the use of microfoundations with optimizing rational agents [5]. In other words, since the empirical results of VAR analysis implies that the changes in nominal variables have persistent effects on real variables, a new consensus emerged about the use of the NKPC for theoretical analysis of monetary policy in the past decade.

While theoretically appealing, empirical evidence on the NKPC is far from decisive. There are a number of studies which provide evidence in favor of the NKPC, while the others provide against it. Gali and Gertler [6] and Gali et al. [7] examine the NKPC for the US economy find that expected inflation is almost always important in determining current inflation. Gali et al. [8] have similar results for the euro area. Sbordone [9] and Amato and Gerlach [10] also suggest that the baseline for-wardlooking NKPC provides a reasonably good description of US and European inflation dynamics.

Nevertheless, there are studies which emphasize that forward-looking specifications are not sufficient to capture inflation persistence (Fuhrer and Moore [11], Roberts [12] and Roberts [13], Rudd and Whelan [14,15] and Stock Watson [16]). Ball [17] demonstrates that the model yields the surprising result that announced, credible disinflations lead booms rather than recessions. Fuhrer and Moore [11] argue that it cannot explain why inflation is so persistent. Mankiw [18] emphasizes that it cannot explain why shocks to monetary policy have a delayed and gradual effect on inflation. According to him, these problems may arise from the same source; "although the price level is sticky in this model, the inflation rate can change quickly". In other words, in the NKPC, price stickiness is not translated into inflation stickiness, hence the inflation level can be changed instantaneously in sharp contrast with empirical patterns.

As a consequence, Gali and Gertler [6] extended Calvo's theoretical framework to the so-called hybrid NKPC (HNKPC) by allowing for a fraction of firms that set prices according to a backward looking rule-of thumb. The work of Gali and Gertler made an important contribution to reconciling the NKPC with the data. The hybrid formulation was able to generate more inflation persistence than the usual NKPC.

However, empirical estimates of the hybrid model also have yielded conflicting results and interpretations. On one hand, Fuhrer [19] finds the forward-looking component in inflation to be essentially unimportant. Roberts [13] compares several PC specifications and obtains a large backward-looking component on US data. Estrella and Fuhrer [20] also document the poor fit of a purely forward-looking PC. Jondeau and Le Bihan [21] estimate hybrid model for major euro countries and US using both GMM and ML estimation procedures. They found that forward-lookingness of the inflation dynamics is not altered by the choice of the forcing variable. In contrast, it is strongly affected by the lag and lead structure of infla- 
tion. Henzel and Wollmershaeuser [22] provide evidence in favor of the hybrid NKPC for selected euro zone countries, the US and the UK. They find that in comparison with the rational expectations approach, backward-looking behavior turns out to be more relevant for most countries in their sample. Carriero [23] tests the NKPC without having to estimate its structural parametre and he concludes that according to simple Wald test it does not exist as a combination of price stickiness and firm's backwardness which is consistent with the US data and this might be due to the failure of the joint hypthesis of rational expectations. On the other hand, he stresses that the idea of forward looking price setting behavior should not be entirely disregarded. Söderlind et al. [24] show, in a calibrated model, that a large backward-looking component is needed to replicate the autocorrelation patterns of inflation and output. Jean-Baptiste [25] estimates the NKPC for United Kingdom using survey forecasts of inflation. He finds that, survey-based inflation forecasts make the Phillips Curve predominantly forward looking and the rational expectations assumption of the agents can be misleading. Roeger and Herz [26] propose to test the purely backward-looking Phillips curve and the purely forward-looking Phillips curve against a hybrid Phillips curve via their implications for cumulative output effects of monetary policy shocks. Their empirical evidence is consistent with the forward-looking model. Chorteas et al. [27] examine the asymmetry of the response of inflation across quantiles. They estimate a hybrid NKPC employing two stage quantile regression. Their results suggest that the response of inflation is asymmetric across different quantiles of distribution. When inflation is high, the forward looking component is significant and dominates the backward-looking component.

So, it is clear that the evidence from the studies on the relevancy of the NKPC is mixed and most of the studies investigated it for developed countries. Among the studies which investigate the inflation dynamics in Turkey, Yazgan and Yilmazkuday [28] provide supporting evidence for conventional NKPC and refuting evidence for the hybrid NKPC from 1988 to 2003 data.

The most current study for Turkey made by Saz [29] and he found strong empirical evidence speaking for the conventional NKPC as well for the hybrid NKPC in Turkey using their own newly constructed measure for marginal costs, the marginal cost index.

\section{Empirical Analysis}

\subsection{Model and Data}

Several papers have provided tests of the NKPC via GMM. Gali and Gertler [6], Gali, Gertler and Salido [7,8] and Sbordone [9] have provided estimates of the NKPC clearly supporting the theory that inflation rate responds to expected inflation and real marginal costs. GMM estimates of the models suggest that forward looking term is dominant which means the coefficient on expected inflation rate substantially exceeds the coefficient on lagged inflation rate, moreover, lagged inflation is statically insignificant. On the other hand, Rudd and Whelan $[14,15]$, Stock and Watson [16] and Nason and Smith [30] found that forward-looking term plays a very limited role in explaining inflation dynamics. Because of these empirical results, and the inflation rate is generally written as a linear combination of the expected inflation, lagged inflation and real marginal costs which is called Hybrid NKPC.

$$
\pi_{t}=\gamma_{f} E_{t} \pi_{t+1}+\gamma_{b} \pi_{t-1}+\lambda y_{t}^{d}+\epsilon_{t}
$$

where $\left(\pi_{t}\right)$ is inflation rate, $\left(E_{t} \pi_{t+1}\right)$ is the expected inflation rate, $\left(\pi_{t-1}\right)$ is the lagged inflation and $\left(y_{t}^{d}\right)$ reflects the marginal costs.

Quantile Regression Method (QRM) which is introduced by Koenker and Basset [31] enables us to estimate the effects of explanatory variables on inflation rate through its distribution ${ }^{3}$. This method has an asymmetric loss function which is based on minimization of asymmetrically weighted sum of absolute errors ${ }^{4}$.

$$
\min _{\beta} V_{t}(\beta)=\sum_{t} \tau\left|\xi_{t}^{+}\right|+(1-\tau)\left|\xi_{t}^{-}\right|
$$

where $\zeta_{t}$ is the error term for $\left|\pi_{t}-X_{t}^{\prime} \beta\right|$ reflects $\xi_{t}^{+}=\pi_{t} \geq X_{t}^{\prime} \beta$ and $\xi_{t}^{-}=\pi_{t}<X_{t}^{\prime} \beta . \pi_{t}$ is inflation rate, $X_{t}$ is the matrix of all explanatory variables and $\beta$ is the coefficient vector. In quantile regression, results are a function of $\tau$. The $\tau$ value below $0.50(\tau<0.45)$ implies more weights on negative residuals, on the other extreme, the $\tau$ value above $0.50(\tau>0.55)$ implies more weights on positive residuals. Qunatile regression also includes as a special case of Least Absolute Deviation (LAD) model, when $\tau=0.50$.

The quantile regression coefficient (say $\gamma_{f}$ ) tells us that for every one unit change in expected inflation will change inflation rate as the value of coefficient at a specific quantile $\left(\tau^{*}\right)$, when Equation (2) is minimized with respect to $\beta$. The conditional quantile function of $\pi_{t}$ at a specific quantile of $\tau^{*}$ given $X_{t}$ may be defined as;

$$
q_{\left(\tau^{*}\right)}\left(\pi_{t} \mid X_{t}\right)=X_{t}^{\prime} \beta+F^{-1}\left(\tau^{*}\right)
$$

Which can be rewritten as

\footnotetext{
${ }^{3}$ Koenker and Basset (1978) ran a simple Monte Carlo experiment and show how the empirical variance of the median, compared to the variance of the mean, is delicately higher under the normal distribution, but it is much lower under all the other distributions taken into consideration.

${ }^{4} \mathrm{As}$ the quantile regression uses absolute values instead of squares it is also more robust and less sensitive to outliers.
} 


$$
q_{\left(\tau^{*}\right)}\left(\pi_{t} \mid E_{t} \pi_{t+1}, \pi_{t-1}, y_{t}^{d}\right)=\gamma_{f} E_{t} \pi_{t+1}+\gamma_{b} \pi_{t-1}+F^{-1}\left(\tau^{*}\right)
$$

QRM is inconsistent and might have to be replaced by the TSQR since the NKPC is likely to have an endogeneity problem arises from possible correlation of error terms with the expected inflation. In the first step we estimated an OLS regression of $\pi_{t+1}$ and $y_{t}^{d}$ on an instrument set. In the second step, we replaced $\pi_{t+1}$ and $y_{t}^{d}$ with their fitted values then estimate the hybrid NKPC using quantile regression ${ }^{5}$.

The hybrid NKPC model is shown in Equation (1), but since Turkey is a small-open economy, exchange rate $\left(e_{t}\right)$ also has an impact on inflation rate. We can extend the NKPC as follows;

$$
\pi_{t}=\gamma_{f} E_{t} \pi_{t+1}+\gamma_{b} \pi_{t-1}+\lambda y_{t}^{d}+\delta e_{t}+\epsilon_{t}
$$

The data used in this study are inflation rate, expected inflation rate, output gap and nominal exchange rate which are covering the period 2002q1-2012q3. Inflation rate is the quarterly change of Consumer Expectation Price Index which is derived from inflation expectations for 12 months period and output gap proxies the marginal cost and calculated by HP Filters which these variables are seasonally adjusted with TRAMO-SEATS. The nominal exchange rate series were calculated as the Turkish lira value of the official basket (1 USD + 0.77 EUR) of the Central Bank of the Republic of Turkey (CBT) prior to the 2001 crisis $^{6}$. For the GMM estimates, the instrument variables are the three lags of inflation, three lags of inflation expectations, two lags of output gap a done lag of exchange rate. In addition, for the effects of 2008 crisis dummy variables are used for the period of 2009q2$2010 \mathrm{q} 1$.

$$
\begin{aligned}
\min _{\beta} V_{t}(\beta)= & \tau \sum_{t \in\left\{t: y_{t} \geq X_{t}^{\prime} \beta\right\}}\left|\pi_{t}-X_{t}^{\prime}\right| \\
& +(1-\tau) \sum_{t \in\left\{t: y_{t}<X_{t}^{\prime} \beta\right\}}\left|\pi_{t}-X_{t}^{\prime}\right|
\end{aligned}
$$

\subsection{Results}

The estimations of the NKPC for Turkey over 2002-2012 are presented below. According to our OLS and GMM estimations all variables are significant. The QRM estimations shows the effects of explanatory variables on inflation rate through its distribution.

${ }^{5}$ Kim and Muller (2004) presented the asymptotic properties of two stage quantile regression estimators with random regressors, where the first stage is based on quantile regressions with the same quantile as in the second stage, which ensures robustness of the estimation procedure. They show that TSQR estimators based on OLS predictions are consistent. Thus, we use past values of inflation and marginal costs as instruments in the context of the NKPC.

${ }^{6}$ Prior to adoption of euro, the official basket of the CBRT consisted of 1 USD and 1.5 DEM. Indeed, 0.77 is obtained by dividing 1.5 by 1.955821 , which is the DEM equivalent of one euro.
Estimation Results

\begin{tabular}{cccccc}
\hline \multirow{2}{*}{ OLS } & & \multicolumn{4}{c}{ 2002: Q1-2012: Q3 } \\
\hline GMM & & $0.27^{* *}$ & $0.39^{*}$ & $0.13^{* *}$ & $0.10^{*}$ \\
& 0.15 & $0.40^{*}$ & $0.62^{*}$ & $0.21^{*}$ & $0.16^{*}$ \\
& 0.20 & 0.23 & 0.24 & 0.12 & 0.07 \\
& 0.25 & 0.23 & 0.12 & 0.07 & 0.05 \\
& 0.30 & 0.21 & $0.43^{* *}$ & $0.15^{* *}$ & $0.08^{* *}$ \\
& 0.35 & 0.19 & $0.39^{* *}$ & 0.12 & 0.06 \\
& 0.40 & 0.17 & $0.46^{* *}$ & $0.14^{* *}$ & 0.06 \\
& 0.45 & 0.25 & $0.52^{*}$ & $0.11^{* *}$ & $0.07^{* * *}$ \\
\hline \multirow{2}{*}{ QRM } & 0.50 & 0.22 & $0.54^{*}$ & $0.13^{* * *}$ & $0.08^{* *}$ \\
& 0.55 & 0.24 & $0.52^{*}$ & 0.14 & $0.10^{*}$ \\
& 0.60 & 0.24 & $0.52^{*}$ & $0.15^{*}$ & $0.11^{*}$ \\
& 0.65 & 0.28 & $0.49^{*}$ & $0.13^{* *}$ & $0.13^{*}$ \\
0.70 & 0.26 & $0.51^{* * *}$ & $0.14^{* *}$ & $0.14^{*}$ \\
& 0.75 & $0.35^{* * *}$ & $0.47^{*}$ & $0.19^{*}$ & $0.12^{*}$ \\
& 0.80 & $0.36^{* * *}$ & $0.48^{*}$ & $0.19^{*}$ & $0.11^{*}$ \\
0.85 & $0.39^{* * *}$ & $0.42^{*}$ & $0.20^{*}$ & $0.10^{* *}$ \\
\hline
\end{tabular}

${ }^{*} 1 \%,{ }^{* *} 5 \%,{ }^{* * *} 10 \%$. Coefficient variances are computed using Huber-Sandwich method. The sparsity function is estimated through Siddiqui mean fitted method using the bandwidth method of Hall-Sheather.

The QRM results demonstrate that the marginal effects of explanatory variables on inflation rate through its distribution is varying. When the inflation rate is low, the backward looking term is significant, notwithstanding forward looking term is insignificant. But when the inflation rate is high, the significance of forward looking term dominates the backward looking term. In addition, the significance of output gap and exchange rates increases for high inflation. It reflects that inflation rate is relatively more driven by lagged inflation when the inflation rate is low, but on the contrary, it is relatively more driven by the policy rate and forming of economic agents' inflation expectations when the inflation rate is high. The importance of backward-looking component through whole quantiles can be explained by the imperfect credibility of the monetary authority.

Thus our results for Turkey Phillips curve suggest that it becomes purely backward-looking at the low inflation quantiles while it becomes hybrid one at high quantiles.

\section{Conclusions}

The empirical evidence on the efficiency of monetary 
policies on real variables discredited the policy ineffectiveness proposition of New Classical paradigm and New Keynesian models based on nominal rigidities have been widely acknowledged in 1990s. New Keynesian Phillips Curve which presents a model of inflation dynamics, postulates that current inflation is determined by expected inflation (forward-looking behavior) and the real marginal costs. By the contributions of Gali and Getrler [6] a hybrid NKPC which includes backward component is suggested.

Despite it has a commonly accepted theoretical background, the evidence from the studies on the relevancy of the NKPC is mixed. While some studies provide the evidence supporting the NKPC, there are also studies which have evidence against it.

In this paper, the Quantile Regression Method (QRM) is used to estimate the New Keynesian Phillips Curve (NKPC) for Turkey. By this method, it is aimed that to identify differences in response of the inflation to changes in explanatory variables at various points of inflation. For the period of 2002q1-2012q3, we find that the backward-looking component appears to be the significant variable at all inflation quantiles and it is especially influential at low levels. In other words, Phillips curve is purely backward-looking at these quantiles. One explanation for this might be the imperfect credibility of the monetary authority. Impact of the forward-looking inflation terms becomes more significant when the inflation increases and it dominates the backward-looking term at high inflation quantiles. In addition, the significance of output gap (marginal cost) and exchange rates increases for high inflation. These findings support the hybrid New Keynesian Phillips curve for Turkish economy over 2002-2012.

\section{REFERENCES}

[1] B. Snowdon and H. Vane, "Modern Macroeconomics; Its Origins, Development and Current State," 2005.

[2] J. Taylor, "Aggregate Dynamics and Staggered Contracts," The Journal Of Political Economy, Vol. 88, No. 1, 1980, pp. 1-23. doi:10.1086/260845

[3] J. J. Rotemberg, "Monopolisitic Price Adjustment and Aggregate Out-Put," Review of Economic Studies, Vol. 49, 1982, pp. 517-531. doi:10.2307/2297284

[4] G. Calvo, "Staggered Prices in a Utility Maximizing Framework," Journal of Monetary Ecoomics, Vol. 12, No. 3, 1983, pp. 383-398. doi:10.1016/0304-3932(83)90060-0

[5] R. Nunes, "Inflation Dynamics: The Role of Expectations," Journal of Money, Credit and Banking, Vol. 42, No. 6, 2010, pp. 1161-1172. doi:10.1111/j.1538-4616.2010.00324.x

[6] J. Gali and M. Gertler, "Inflation Dynamics: A Structural Econometric Analysis," Journal of Monetary Economics, Vol. 44, No. 2, 1999, pp. 195-222. doi:10.1016/S0304-3932(99)00023-9
[7] J. Gali, M. Gertler, et al., "European Inflation Dynamics," Journal of Monetary Economics, Vol. 45, No. 7, 2001, pp. $1237-1270$

[8] J. Gali, M. Gertler, et al., "Robustness of the Estimates of Hybrid New Keynesian Phillips Curve," Journal of Monetary Economics, Vol. 52, No. 6, 2005, pp. 11071118. doi:10.1016/j.jmoneco.2005.08.005

[9] A. Sbordone, "Inflation Persistence: Alternative Interpretations and Policy Implications," Journal of Monetary Economics, Vol. 54, No. 5, 2007, pp. 1311-1339. doi:10.1016/j.jmoneco.2007.06.007

[10] J. Amato and S. Gerlach, "Inflation Targeting in Emerging Market and Transition Economies, Lessons after a Decade," Centre for Economic Policy Research, 2001.

[11] J. Fuhrer and M. Gerald, "Inflation Persistence," Quarterly Journal of Economics, Vol. 110, No. 1, 1995, pp. 127-159. doi:10.2307/2118513

[12] J. Roberts, "Inflation Expectations and the Transmission of Monetary Policy," Board of Governors of the Federal Reserve System, 1998.

[13] J. Roberts, "How Well Does The New Keynesian Sticky-Price Model Fit the Data?" Federal Rezerve Board FEDS Working Papers, 2001, pp. 1948-1943.

[14] J. Rudd and K. Whelan, "New Tests of The New Keynesian Phillips Curve," Journal of Monetary Economics, Vol. 52, No. 6, 2005, pp. 1167-1181. doi:10.1016/j.jmoneco.2005.08.006

[15] J. Rudd and K. Whelan, "Modeling Inflation Dynamics: A Critical Review of Recent Research," Journal of Money, Credit and Banking, Vol. 39, No. 1, 2007, pp. 155-170. doi:10.1111/j.1538-4616.2007.00019.x

[16] J. Stock and M. Watson, "Why Has US Inflation Become Harder To Forecast?" Journal of Money, Credit and Banking, Vol. 39, No. 1, 2007, pp. 3-34. doi:10.1111/j.1538-4616.2007.00014.x

[17] L. S. Ball, "Near-Rationality and Inflation in Two Monetary Regimes," NBER Working Paper, 2000.

[18] N. G. Mankiw and R. Reis, "Sticky Information Versus Sticky Prices: A Proposal to Replace the New Keynesian Phillips Curve," Harvard University, Cambridge, 2001.

[19] J. C. Fuhrer, "The (un)Importance of Forward-Looking Behavior in Price Specifications," Journal of Money, Credit and Banking, Vol. 29, No. 3, 1997, pp. 338-350. doi: $10.2307 / 2953698$

[20] A. Estrella and J. Fuhrer, "Dynamic Inconsistincies: Counterfactual Implications of a Class of Rational Expectations Models," The American Economic Review, Vol. 92, No. 4, 2002, pp. 1013-1028. doi: $10.1257 / 00028280260344579$

[21] E. Jondeau and H. Le Bihan, "Testing for The New Keynesian Phillips Curve; Additional International Evidence," Economic Modelling, Vol. 22, No. 3, 2005, pp. 521550. doi:10.1016/j.econmod.2004.09.002

[22] S. Henzel and T. Wollmershaeuser, "The New Keynesian Phillips Curve and the Role of Expectations: Evidence From the Ifo World Economic Survey," CESifo Working Paper, 2006.

[23] A. Carriero, "A Simple Test of the New Keynesian Phi- 
llips Curve," Economic Letters, Vol. 100, No. 2, 2008, pp. 241-244. doi:10.1016/j.econlet.2008.02.012

[24] P. Söderlind, U. Söderström and A. Vredin, "Can a Calibrated New-Keynesian Model of Monetary Policy Fit the Facts?" SSE/EFI Working Paper Series in Economics and Finance No. 511, 2002.

[25] F. Jean-Baptiste, "Forecasting with the New Keynesian Phillips Curve: Evidence from Survey Data," Economic Letters, Vol. 117, No. 3, 2012, pp. 811-813. doi:10.1016/j.econlet.2011.02.034

[26] W. Roeger and B. Herz, "Traditional Versus New Keynesian Phillips Curves; Evidence from Output Effects," International Journal of Central Banking, 2012, pp. 87109.

[27] G. Chorteas, G. Magonis and T. Panagiotidis, "The Asymmetry of the New Keynesian Phillips Curve in the EuroArea," Economic Letters, Vol. 114, No. 2, 2012, pp. 161163. doi:10.1016/j.econlet.2011.09.035
[28] M. E. Yazgan and H. Y1lmazkuday, "Inflation Dynamics of Turkey: A Structural Estimation," Studies in Nonlinear Dynamics \& Econometrics, Vol. 9, No. 1, 2005, pp. 1-13. doi:10.2202/1558-3708.1228

[29] G. Saz, "The Turkish Phillips Curve Experience and the New Keynesian Phillips Curve: A Conceptualization and Application of a Novel Measure for Marginal Costs," International Research Journal of Finance and Economics, Vol. 63. 2011, pp. 8-45.

[30] J. M. Nason and G. W. Smith, "The New Keynesian Phillips Curve: Lessons from Single-Equation Econometric Estimation," Economics Quarterly, Vol. 94, No. 4, 2008, pp. 667-684.

[31] R. Koenker and G. Basset, "Regression Quantiles," Econometrica, Vol. 46, No. 1, 1978, pp. 33-50. doi: $10.2307 / 1913643$ 